Article - Human and Animal Health

\title{
Oral Administration of Incense Resin (Styrax benzoin) Extract Enhances Spatial Learning, Memory, and Dendrite Complexity of Mice
}

\author{
Kamila Alawiyah ${ }^{1}$ \\ https://orcid.org/0000-0001-7289-446X \\ Berry Juliandi ${ }^{*}$ \\ https://orcid.org/0000-0003-0348-5675 \\ Arief Boediono ${ }^{3}$ \\ https://orcid.org/0000-0003-1535-703X

\section{Noriaki Sasai ${ }^{4}$} \\ https://orcid.org/0000-0003-0360-1138
}

${ }^{1}$ IPB University (Bogor Agricultural University), Department of Biology, Graduate Program of Animal Biosciences, Bogor, Indoensia; '2IPB University (Bogor Agricultural University), Faculty of Mathematics and Natural Sciences, Department of Biology, Bogor, Indonesia; ${ }^{3}$ PB University (Bogor Agricultural University), Faculty of Veterinary Medicine, Department of Anatomy, Bogor, Indonesia; ${ }^{4}$ Nara Institute of Science and Technology, Developmental Biomedical Science, Division of Biological Sciences, Ikoma, Japan

Received: 2018.07.23; Accepted: 2020.04.01.

*Correspondence: bjuliandi@ipb.ac.id; Tel.: +62-251-8622833

\section{HIGHLIGHTS}

- Incense resin extract increased learning and memory ability.

- Incense resin extract increased the number of dendrite branching in the dentate gyrus.

Abstract: Hippocampus is a part of the brain that has a major role in spatial learning and memory which can be affected by herbal extracts. Incense resin (Styrax benzoin) has been used by local communities to improve intelligence. However, there is no scientific evidence of the functions of Styrax benzoin for regulating hippocampal function. The aim of this study was intended to analyze and investigate the effect of incense resin on learning, memory, and dendrite complexity of mice. Three months old male Deutch Democratic Yokohama (DDY) mice were injected orally with graded doses of 100, 150, and $200 \mathrm{mg} / \mathrm{kg}$ of incense resin aqueous extract daily for 30 days. Spatial learning and memory performance levels were tested with Y-maze alternation, novel object recognition, and Morris water maze. The branches and maximum dendritic span in the dentate gyrus were observed by the Golgi-Cox staining. Overall, our results showed that incense resin extract increased learning and memory ability, and the number of dendrite branching in the dentate gyrus.

Keywords: incense resin; kemenyan; learning-memory; dendrite complexity. 


\section{INTRODUCTION}

Learning is the process of getting new information that can affect behavior. Spatial learning for example, is required in the direction of movement from environmental guidance. This process also needs storing and generating information in the form of memory by the brain, which is coordinate all of these related events [1]. Hippocampus is a part of the brain that has a major role in the spatial learning and memory process, and in particular, the dentate gyrus of hippocampus contributes to adult neurogenesis. Neurogenesis is the process of forming new functional neurons from neural stem cells. The formation of neurons further develops into neural networks. Newly formed neural networks have been shown to improve learning and memory performance [2]. The process of neurogenesis is influenced by many factors, one of which has been suggested to be chemical(s) extracted from herbs.

Incense resin (Styrax benzoin), one of the native plants of Indonesia [3], has been used traditionally by local communities as an enhancer of brain intelligence. Another type of incense that classified into genus Boswellia is a native plant in the middle east [4], and the functions of its resin have been widely studied to improve learning and memory performance [5]. However, research on effects of Indonesian incense resin on the brain function has never been conducted to date. The aim of this study was to investigate the effect of Indonesian incense resin (Styrax benzoin) on the learning and memory performance and dendrite complexity in mice.

\section{MATERIAL AND METHODS}

\section{Aqueous extraction}

Incense (Styrax benzoin) resin was provided by the farmers in Northern Sumatra, Indonesia. The extraction of incense resin was done by aqueous extraction technique. Dry solid resin of incense was smoothed until it became powder form, and filtered with wire mesh (size 100). The powder forms were dissolved in the aqueous solvent with maceration method for 3 days in $25^{\circ} \mathrm{C}$. The concentration of powder preparations with aqueous solvents was $10 \%(\mathrm{w} / \mathrm{v})$. The solution was filtered to separate the dregs with water and the solute. The soluble substances in the solvent were further purified by evaporation [6].

\section{Animal subject maintenance}

This research was approved by Animal Ethics Committee of Bogor Agricultural University (No. 732017.IPB). Thirty young male Deutch Democratic Yokohama (DDY) mice strain (25-30 grams of body weight) were kept in cages, in the animal house with the conditions of $22-25{ }^{\circ} \mathrm{C}$ of temperature, $55-63 \%$ of humidity and $12 \mathrm{~h}$ light and dark lighting cycle. Mice were given with standard rodent diet ad libitum until the euthanasia process.

\section{Treatment}

This study used 30 male mice divided into 5 different treatment groups. Mice were acclimatized for 7 days before the starting of the treatment. Oral treatment was administered every day for 30 days. The negative control group was administered $0.3 \mathrm{ml}$ of water (vehicle); the positive control group was administered with leaf extract of pegagan (130 mg/kg body weight) [7] in $0.3 \mathrm{ml}$ vehicle; and the test group was administered with extract of incense sap (100,150, and $200 \mathrm{mg} / \mathrm{kg}$ of the body weight) in $0.3 \mathrm{ml}$ vehicle [8].

\section{Behavior analysis using Y-alternation test}

Y-alternation test was carried out to assess the spatial learning performance according to Juliandi and coauthors [9]. The Y-arm maze apparatus consisted of three arms. The test was performed twice in each test. First test was performed before treatment administration, and second test was performed at $24 \mathrm{~h}$ after the last administration. Individual mouse was placed in the middle of three arms and the number of correct sequences during five minutes were recorded. Correct sequence was indicated by the mice which can enter three different arms. The test measurement was calculated by correct percentage of mice in exploring the arms of the apparatus. Correct percentage is the number of correct sequences divided by the total sum of all sequences. 


\section{Behavior analysis using novel object recognition test}

The novel object recognition (NOR) test was carried out to assess the memory ability. The principle of this test is to assess the tendency of mice to spend more time exploring a novel object than a previously explored object. Mice with good memory have a tendency to explore new objects or objects in addition to familiar objects. This NOR test was performed in accordance with the method by Bevins and Basheer [10]. NOR test consists of familiarization and test phase. Familiarization phase was when the mice was introduced with two identical objects for ten minutes. This object was defined the familiar object. The test phase was conducted by replacing one of the objects with new object. The mice were allowed to explore within the apparatus for 3 minutes. The test results were analyzed by calculating the discrimination ratio. Discrimination ratio is comparison between novel object interaction and total interaction with both objects.

\section{Behavior analysis using morris water maze test}

The Morris water maze (MWM) test was performed in accordance with the method by Weitzner and coauthors [11] with a few modifications. Mice were tested with MWM method to assess the learning and memory performance by putting local cues so that mice could learn and remember the position. The apparatus was constructed with round tub. The tub was 1.5 meters in diameter and 0.7 meter in height. MWM test consisted of training and real test phase. Training phase consisted of a visible trial and a hidden platform trial. Mice were allowed to find the visible platform easily in a visible trial because the platform was upper of the water surface. An invisible trial was used in an invisible platform which the platform was below of the opaque water. Short term memory and long-term memory were assessed with this method. Mice were allowed to find the platform of each phase within one minute. The test result was analyzed by calculating the latency time. Latency time is the performance indicator learning and memory in the task.

\section{Dendritic morphology analysis using golgi-cox staining}

The mice were anaesthetized using ketamine/xylazine [12]. The brain was isolated for Golgi-Cox staining. Golgi-cox staining enabled the visualization of neurons (soma, axons, and dendrites) in a selective way. This could help the researchers to characterize and quantify dendritic morphology and spines throughout the nervous system [13,14]. The procedural of Golgi-Cox staining was according to the factory-supplied protocol (FD Neuro Technologies, Inc.). The number of dendritic branching and maximum dendritic span in the dentate gyrus was analyzed by using the ImageJ software.

\section{Statistical analysis}

The data was analyzed using SPSS 16 software. For Y-alternation and novel object recognition test (e.g. the comparison of treatment), the data were analyzed by using one-way ANOVA, while the comparisons of the pre- and post-treatment were made by using a paired t-test; Morris water maze data (e.g. the comparison of treatment) was analyzed using one-way ANOVA while before and after treatment were analyzed using paired t-test; and to compare each treatment was analyzed by using independent t-tests.

\section{RESULTS}

\section{Spatial learning performance}

One part of the brain that plays a role in spatial learning is the hippocampus. Y-alternation test was carried out to determine the spatial learning ability of mice brain. The percentage of correct sequence in the administration of herbal extracts can indicate the learning ability of mice (Figure 1). 


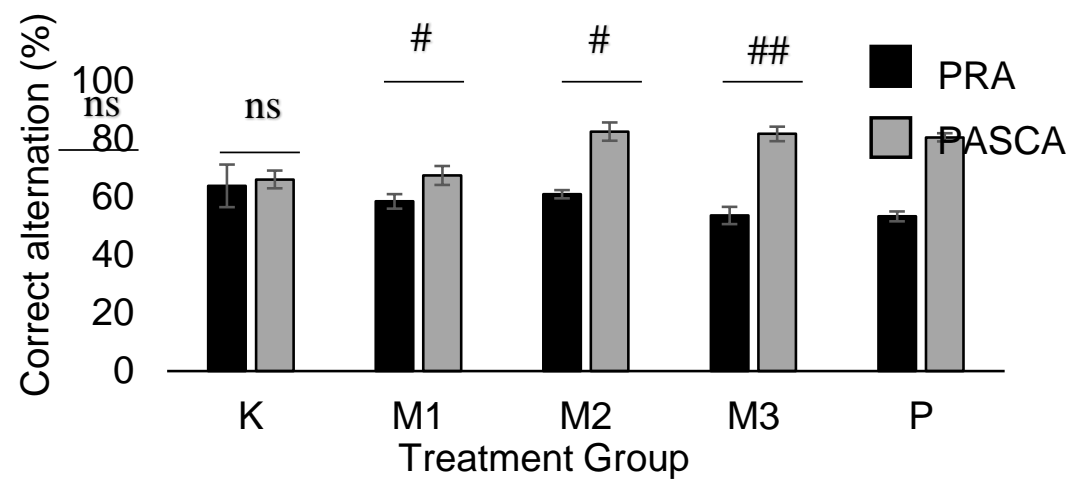

Figure 1. Spatial learning performance of mice in $\mathrm{Y}$-maze improves by herbs administration. Control group (K), incense resin extract $100 \mathrm{mg} / \mathrm{kg}$ body weight (M1), $150 \mathrm{mg} / \mathrm{kg}$ body weight (M2), $200 \mathrm{mg} / \mathrm{kg}$ body weight (M3), and pegagan (P). Before treatment (PRA), after Treatment (PASCA). Error bars indicate the SD. $\# p<0.05$, \#\#p<0.01, paired $t$-test; ns= not significant.

\section{Long-Term Memory Performance with Novel Object Recognition Test}

Short-term and long-term memory ability was tested with novel object recognition (NOR) tests. The short or long term memory test was determined by the delay time. The delay time that has been used was 30 days. Figure 2 shows the effect of herbal extracts administration on long-term memory.

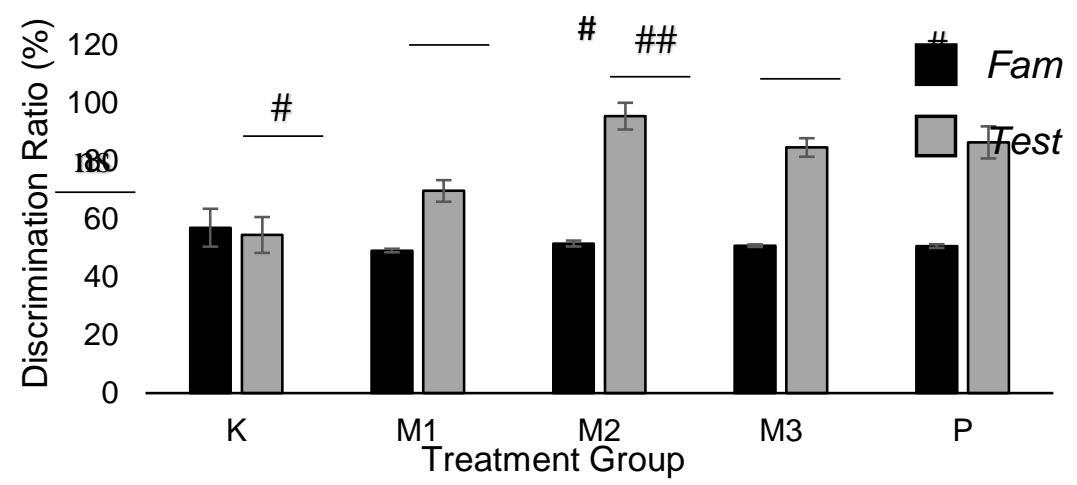

Figure 2. Herbs extract administration enhances short term memory (STM) performance of mice in novel object recognition (NOR) test. Control group (K), incense resin extract group $100 \mathrm{mg} / \mathrm{kg}$ body weight (M1), $150 \mathrm{mg} / \mathrm{kg}$ body weight (M2), $200 \mathrm{mg} / \mathrm{kg}$ body weight (M3), and pegagan (P). Familiarization phase (Fam) and test phase (Test). Error bars indicate the SD. $\# p<0.05, \# \# p<0.01$ paired $t$-test; ns= not significant.

\section{Learning and memory performance with Morris water maze test}

The Morris water maze test (MWM) is a universally recognized method for measuring and comparing learning and memory abilities [15]. Learning ability was measured during training. Short-term memory ability can be measured by a delay of one day after training, while long-term memory abilities were measured by one month delay. 

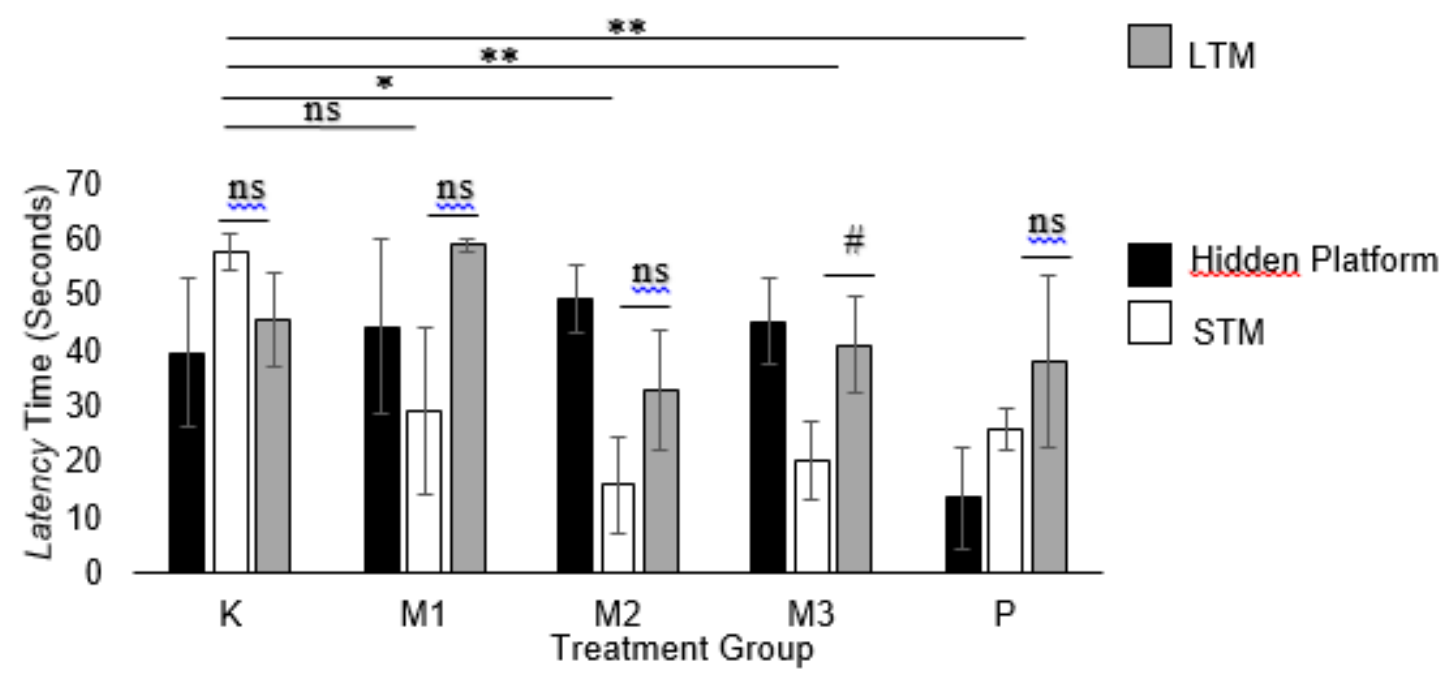

Figure 3. Herbs extract administration effect on the learning test (Hidden Platform), short term memory test (STM), and long-term memory test (LTM) performance of mice using morris water maze (MWM). Control group (K), incense resin extract $100 \mathrm{mg} / \mathrm{kg}$ body weight (M1), $150 \mathrm{mg} / \mathrm{kg}$ body weight (M2), $200 \mathrm{mg} / \mathrm{kg}$ body weight (M3), and pegagan extract (P). Error bars indicate the SD. ${ }^{*} p<0.05,{ }^{* *} p<0.01$, independent $t$-test; $\# p<0.05$, paired $t$-test; $\mathrm{ns}=$ not significant.

\section{Complexity and Maximum Dendritic Span of Neurons}

One part of the hippocampus that plays an important role in learning and memory is Dentate Gyrus (DG). The process of neurogenesis can occur in DG. The process of neurogenesis plays a role in producing functional adult neurons. These functional neurons can be observed using Golgi-cox dyes. This Golgi-cox staining method colored the entire neuron cell including the cell body, axons, and dendrites [14]. The neurons in the DG section can be colored using the Golgi-cox dye (Figure 4).

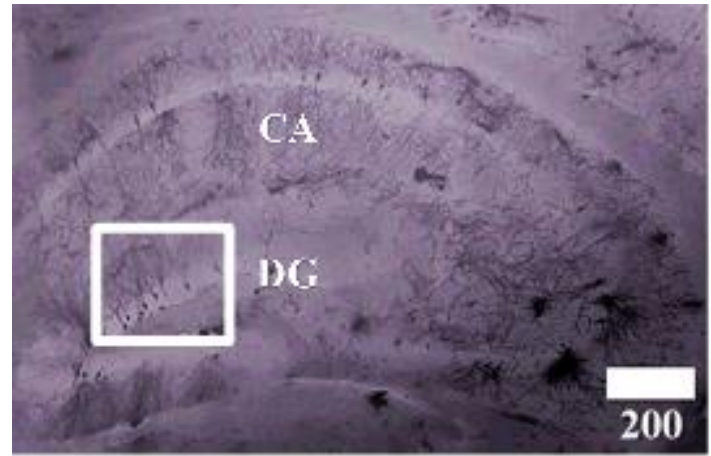

(a)

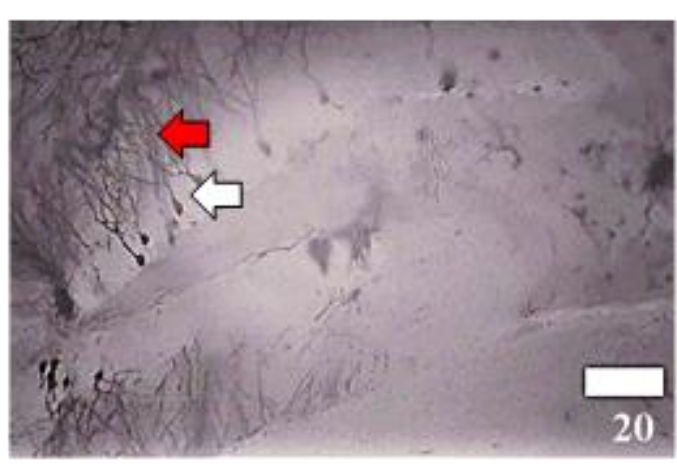

(b)

Figure 4. Representative image of mice hippocampus (a) stained by Golgi-Cox method, showing CA and DG (dentate gyrus; b). The white arrow indicated the cell body and red arrow indicated dendrites.

Golgi-cox staining allows researchers to analyze the morphology of neurons. The morphology analyzed was the average average number of dendrite branches (Table 1) and the maximum dendritic span (Table 2). Dendrites are part of nerve cells that function to receive stimuli from other nerve cells through the synapse and continue to stimulate the cell body. Nerve cells have many branches of dendrites because dendrites can make connections between many other nerve cells. 
Table 1. The average number of branches and maximum dendritic span in the dentate gyrus

\begin{tabular}{ccc}
\hline Group & $\begin{array}{c}\text { Average number of dendrite } \\
\text { branches }(\mu \mathrm{m})\end{array}$ & Maximum dendritic span (०) \\
\hline Control & $2.22 \pm 0.34^{\mathrm{a}}$ & $57.16 \pm 1.40^{\mathrm{a}}$ \\
Incense resin dose $100 \mathrm{mg} / \mathrm{kg} \mathrm{BW}$ & $2.00 \pm 0.31^{\mathrm{a}}$ & $55.98 \pm 0.92^{\mathrm{a}}$ \\
Incense resin dose $150 \mathrm{mg} / \mathrm{kg} \mathrm{BW}$ & $3.27 \pm 0.35^{\mathrm{b}}$ & $55.50 \pm 1.41^{\mathrm{a}}$ \\
Incense resin dose $200 \mathrm{mg} / \mathrm{kg} \mathrm{BW}$ & $4.45 \pm 0.50^{\mathrm{c}}$ & $54.47 \pm 0.89^{\mathrm{a}}$ \\
Pegagan (positive control) & $5.86 \pm 0.68^{\mathrm{c}}$ & $57.08 \pm 0.69^{\mathrm{a}}$ \\
\hline
\end{tabular}

Numbers followed by the same letter in the same column are not significantly different.

$\left({ }^{a-b}=p<0.05 ;{ }^{b-c}=p<0.001\right)$.

\section{DISCUSSION}

The comparison of spatial learning performance is shown in Figure 1. The correct alteration for the whole group of mice before administration of herbal extracts were not significant ( $p=0.29$; one-way ANOVA). This indicates that spatial learning of mice that used in the study was not characteristically different. Spatial learning ability before and after treatment in the control group was not significantly different $(p=0.79$; paired $\mathrm{t}$-test). This suggests that the presence of $\mathrm{Y}$-maze test at the beginning was not affect the ability of mice to resolve Y-maze test.

The correct alteration of the mice after herbal extracts administration was significantly different $(p=0.002$; one-way ANOVA). This result showed that the spatial learning ability was influenced by herbal extract administration. However, before and after administration of incense resin extract with doses of $100 \mathrm{mg} / \mathrm{kg}$, the body weight was not significantly different $(p=0.13$; paired t-test). Incense resin extract with dose of 100 $\mathrm{mg} / \mathrm{kg}$ body weight was not able to improve spatial learning ability in the mice. Paired t-test analysis result shows that the correct alteration data before and after incense resin $(150,200 \mathrm{mg} / \mathrm{kg}$ body weight) and pegagan extract administration increased significantly.

The effect of herbal extracts administration on long-term memory is presented in Figure 2. The discriminant ratio of all mice to the exploration of the same two objects at the familiarization stage was $\pm 50 \%$. This result showed that exploration amount of two object was not different. One-way ANOVA result for all treatment at the familiarization stage was not significantly different $(p=0.44)$. This result showed that memory performance of the mice used in this study were characteristically comparable. Memory performance after herb extract administration increased ( $p=0.0009$; ANOVA one-way). Discrimination ratio between familiarization stage and test in group treatment of incense resin and pegagan extract showed significant result. This result showed that extract group of incense resin and pegagan improved the memory. Effect of incense resin extract administration and positive control (pegagan) was similar or not significantly different $(p=0.27$; ANOVA one-way).

The results of the analysis test using one-way ANOVA showed not significant results for hidden stage platform trial for all treatments (Figure 3). This result showed that long term memory performance was not significantly different for all group treatments. Short term memory performance for incense resin (150 and $200 \mathrm{mg} / \mathrm{kg}$ body weight) and pegagan extract administration increased significantly. However, the independent t-test result of incense resin extract $(100 \mathrm{mg} / \mathrm{kg}$ body weight) showed not significant results $(p$ $=0.13)$. Short term memory performance of the mice in the incense resin extract $(200 \mathrm{mg} / \mathrm{kg}$ body weight) group was better than long-term memory performance ( $p=0.02$; paired t-test).

$Y$-alternation test was performed to determine the spatial learning performance of the mice brain. The NOR test was performed to test the ability of long term memory with a 30 days delay time before test phase. The MWM test was used to measure and compare learning and memory performance [5]. Learning performance was measured during training. Short term memory performance was measured with a 1 day delay time after training, while long term memory performance was measured after 30 days delay time. This study used three doses of incense resin extract $(100,150$, and $200 \mathrm{mg} / \mathrm{kg}$ body weight). Incense resin extract (100 mg/kg body weight) administration did not affect spatial learning performance. However, incense resin extract (150 and $200 \mathrm{mg} / \mathrm{kg}$ body weight) administration promoted spatial learning performance. This result showed that incense resin extract (150 and $200 \mathrm{mg} / \mathrm{kg}$ body weight) increased spatial learning performance as well as Boswellia serrata resin extract [15-17]. Flavonoid contain from Styrax benzoin extract increased brain-derived neurotrophic factor (BDNF) production. BDNF production regulated differentiation and growth 
of nerve cell [18]. In addition, BDNF stimulated neurogenesis processes [18,19]. Styrax benzoin contained antioxidant agent. Antioxidant also functions as neuroprotective that protects nerve cells from free radicals.

Pegagan extract as positive control increased spatial learning performance. This increment was in the same magnitude shown in the previous study [2]. Pegagan has been known to contain flavonoid that supports the performance of cells in the hippocampus [20]. Incense resin extract with 150 and $200 \mathrm{mg} / \mathrm{kg}$ body weight dose was stronger in short term memory improvement compared with incense resin extract $100 \mathrm{mg} / \mathrm{kg}$ body weight dose. This result was supported by the outcome of the MWM test. Incense resin extract (150 and 200 $\mathrm{mg} / \mathrm{kg}$ body weight) administration increased short term memory. However, incense resin extract $200 \mathrm{mg} / \mathrm{kg}$ body weight administration was stronger in short term memory improvement compared with incense resin extract 100 and $150 \mathrm{mg} / \mathrm{kg}$ body weight. Nevertheless, spatial learning and long-term memory performance was not affected by herb extract administration as shown in MWM results. Differences in the effect of dosage on memory ability were known to be affected by weight, age, and health condition. In this study, spatial learning, short term memory and long-term memory performance was influenced by incense resin extract with dose concentration of 150 and $200 \mathrm{mg} / \mathrm{kg}$ body weight. Incense resin with dose concentration of 100 $\mathrm{mg} / \mathrm{kg}$ body weight was not enough to affect the ability of learning.

The number of dendritic branching after incense resin and pegagan extract administration was significantly different from the control ( $p=0.000$; ANOVA one- way) (Table 1). The number of dendritic branching between control mice group and incense resin mice group (150 and $200 \mathrm{mg} / \mathrm{kg}$ body weight) was significantly different $(p=0.046, p=0.0003$; independent $\mathrm{t}$ - test). However, the number of dendritic branching in $100 \mathrm{mg} / \mathrm{kg}$ body weight group was not significantly different ( $p=0.067$; independent $\mathrm{t}$ - test). Maximum dendritic span in all treatment groups was not significantly different ( $p=0.434$; ANOVA one-way). This result demonstrates that administration of herbal extracts did not affect the maximum dendritic span in the dentate gyrus.

Functional neurons were observed by Golgi-Cox staining. Golgi-Cox staining method coloured the entire cell of neurons including cell body, axon and dendrite [14]. Incense resin extract (150 and $200 \mathrm{mg} / \mathrm{kg}$ body weight) administration increased the number of dendritic branching. However, the number of dendritic branching in $100 \mathrm{mg} / \mathrm{kg}$ body weight group was not increased. The number of dendritic branching affected learning and memory performance. However, the number of dendritic branching was not the only factor that affected the learning and memory performance. Nerve cells had many branches of dendrites because dendrites made connections between many other nerve cells. The number of dendritic branching data was supported by data regarding the maximum dendritic span. Nerve orientation was determined by measuring the maximum dendritic span. Normal dendrites had a high similarity of maximum dendritic span with the control group. In this study, we found that maximum dendritic span for all treatment group was not significantly different with negative control group. This result represents that dendritic span of all mice group was normal. Voets and coauthors [21] suggested that disorientated dendritic span (aberrant) caused epilepsy disease. The aberrant dendrite destructed neuron functions. According to Rao and coauthors [22,23], asiatic acid contained in Pegagan had an antioxidant agent and neurotropic effect. Neuron was protected by antioxidant from free radical and reactive oxygen species (ROS). The protected neuron would be better at performing of storing and managing information.

\section{CONCLUSION}

We found that incense resin extract with doses of 150 and $200 \mathrm{mg} / \mathrm{kg}$ body weight administration improved learning ability, short-term memory, and long-term memory. Incense resin extract with a dose of $100 \mathrm{mg} / \mathrm{kg}$ body weight increased only long-term memory. The effect of resin extract of doses of 150 and $200 \mathrm{mg} / \mathrm{kg}$ body weight on long-term memory was stronger than the dose of $100 \mathrm{mg} / \mathrm{kg}$ body weight. Improved spatial and memory learning performance was in parallel with an increase in the number of neurons branching.

Funding: This work was supported by a grant from the Ministry of Research, Technology, and Higher Education, Indonesia to Berry Juliandi (No. 4101/IT3.L1/PN/2019), and the Global Collaboration Program (NAIST) and grants-inaid from Japan Society of Promotion of Science (No. 17H03684) to Noriaki Sasai.

Acknowledgments: We thank the Ministry of Research, Technology, and Higher Education, Indonesia; the Global Collaboration Program (NAIST) and Japan Society of Promotion of Science.

Conflicts of Interest: The authors declare no conflict of interest.

\section{REFERENCES}


1. Alkon DL, Amaral DG, Bear MF, Black J, Carew TJ, Cohen NJ, et al. Learning and memory. Brain Res Rev. 1991 Aug;16(2):193-220.

2. Praag VH, Kempermann G, Gage FH. Running increases cell proliferation and neurogenesis in the adult mouse dentate gyrus. Nat Neurosci. 1999 Mar;2:266-270.

3. Wyk MV, Wingfield BD, Clegg PA, Wingfield MJ. Ceratocystis larium sp. a new species from Styrax benzoin wounds associated with incense harvesting in Indonesia. Persoonia. 2009 Apr;22:75-82.

4. Safayhi H, Sailer ER. Anti-inflammatory actions of pentacyclic triterpenes. Planta Med. 1997Jul;63:487-493.

5. Jalili C, Salahshoor MR, Pourmotabbed A, Moradi S, Roshankhah SH, Shabanizadeh A, et al. The effects of aqueous extract of Boswellia serrata on hippocampal region CA1 and learning deficit in kindled rats. Res Pharm Sci. 2013 Oct;9:351-358.

6. Sharifabad $\mathrm{MH}$, Esfandiary EA. Morphometeric study on CA3 hippocampal field in young rats following maternal administration of Boswellia serrata resin during gestation. Irani J Basic Med Sci. 2007 Nov;10:176-182.

7. Guo J, Duan JA, Tang Y, Li Y. Sedative and anticonvulsant activities of Styrax after oral and intranasal administration in mice. Pharmaceutic Biol. 2011 Mar;49:1034-1038.

8. Reagen S, Nihal M, Ahmad N. Dose translation from animal to human studies revisited. FASEB J. 2007 Apr;22:659661.

9. Juliandi B, Tanemura K, Igarashi I, Tominaga T, Furukawa Y, Otsuka M, et al. Reduced adult hippocampal neurogenesis and cognitive impairments following prenatal treatment of the antiepileptic drug valproic acid. Stem Cell Res. 2015 Dec;5(6):996-1009.

10. Bevins RA, Besheer J. Object recognition in rats and mice: a one-trial non- matching-to-sample learning task to study 'recognition memory'. Nat protoc. 2006 Oct;1:1306-1311.

11. Weitzner DS, Engler-Chiurazzi EB, Kotilinek LA, Ashe KH, Reed MN. Morris water maze test: optimization or mouse strain and testing environment. J Vis Exp. 2015 Jun;100:1-11.

12. Grimstad O, Sawanobori Y, Vestergaard C, Bilsborough J, Olsen UJ, Larsen CG, et al. Anti-interleukin-31antibodies ameliorate scratching behaviour in NC/Nga mice: a model of atopic dermatitis. Exp Derma. 2009 Jan;18(1):35-43.

13. Gibb R, Kolb BA. Method for vibratome sectioning of Golgi-Cox stained whole rat brain. J Neurosci Meth. 1998 Jan;79(1):1-4.

14. Risher WC, Ustunkaya T, Singh Alvarado J, Eroglu C. Rapid golgi analysis method for efficient and unbiased classification of dendritic spines. PloS one. 2014 Sep;9:1-8.

15. Morris RGM. Development of a water-maze procedure for studying spatial learning in the rat. J Neurosci Meth. 1984 May;11(1):47-60.

16. Kondoril MK, Sadeghi F, Hosseinpourfeizi MA, Hesari FS, Nakhlband A, Yamchi MR. Boswellia serrata gum resin aqueous extract upregulates BDNF but not CREB expression in adult male rat hippocampus. Turk J Med Sci. 2016 Nov; 46(5):1573-1578.

17. Sharifabad MH, Ardakani RK, Sharifabad AH. Beneficial effect of Boswellia serrata gum resin on spatial learning and the dendritic tree of dentate gyrus granule cells in aged rats. AJP. 2016 Apr; 6(2):189-197.

18. Lee $\mathrm{S}$, Kim DH, Lee $\mathrm{DH}$, Jeon $\mathrm{SH}$, Lee $\mathrm{CH}$, Son $\mathrm{KH}$, et al. Oroxylin a, a flavonoid, stimulates adult neurogenesis in the hippocampal dentate gyrus region of mice. Neurochem Res. 2010 Nov;35(11):1725- 1732.

19. Blurton JM, Kitazawa M, Coria HM, Castello NA, Muller FJ, Loring JF, et al. Neural stem cells improve cognition via BDNF in a transgenic mode of Alzheimer disease. Proc Natl Acad Sci U S A. 2009 Aug;106(32):13594-13599.

20. Zheng CJ, Qin LP. Chemical components of Centella asiatica and their bioactivities. J Chin Integre Med. 2007 May;5(3):348-351.

21. Voets NL, Zamboni G, Stokes MG, Carpenter K, Stacey R, Adcock JE. Aberrant functional connectivity in dissociable hippocampal networks is associated with deficits in memory. J Neurosci. 2014 Apr;34(14):4920-4928.

22. Rao SB, Chetana M, Devi PU. Centella asiatica treatment during postnatal period enhances learning and memory in mice. Physiol Behav. 2005 Nov;86:449-457.

23. Kumar MHV, Gupta YK. Effect of different extracts of Centella asiatica on cognition and markers of oxidative stress in rats. J Ethnopharmacol. 2002 Feb;79:253 - 60 